\title{
Reuse of Organisational Experience Harnessing Software Agents
}

\author{
Krzysztof Krawczyk ${ }^{1}$, Marta Majewska ${ }^{1}$, Mariusz Dziewierz ${ }^{1}$, Renata Słota ${ }^{2}$, \\ Zoltan Balogh ${ }^{3}$, Jacek Kitowski ${ }^{1,2}$, and Simon Lambert ${ }^{4}$ \\ 1 ACC CYFRONET-AGH, ul. Nawojki 11, 30-950 Cracow, Poland \\ $\{$ krafcoo,mmajew, aristot\}@icsr.agh.edu.pl \\ 2 Institute of Computer Science, AGH-UST, al. Mickiewicza 30, Cracow, Poland \\ $\{$ rena, kito\}@agh.edu.pl \\ 3 Institute of Informatics, SAS, Dubravska cesta 9, 84507 Bratislava, Slovakia \\ balogh.ui@savba.sk \\ ${ }^{4}$ CCLRC Rutherford Appleton Laboratory, Chilton, Didcot, OX11 0QX, UK \\ S.C.Lambert@rl.ac.uk
}

\begin{abstract}
This paper presents the application of agent technology for managing employee's experience within an organisation. The proposed approach is discussed on the basis of the software platform developed within the scope of the EU IST Pellucid project. The system is intended to provide universal assistance for organisationally mobile employees. Its functionality is realized by a set of agents. The focus of this paper is on reuse of organisational experience, which is transmitted by active hints. The experience is structured using ontologies.
\end{abstract}

\section{Introduction}

An agent-based experience management system is being developed within the scope of the EU IST Pellucid project (IST-2001-34519) [1], as a response to needs formulated by many organisations to reuse their employees' experience. The Pellucid system is aimed at departments of organisations that are characterized by a high level of staff rotation which results in reduced efficiency and consequent losses. The Pellucid system allows the capturing of employees' experience and reusing it to assist other employees in a similar position in the future. It also assists a mobile employee to reuse his knowledge at a new position within the organisation. The paper discusses the use of agents for experience management in the Pellucid platform. Certain aspects of experience management have been already described in [2/34/5].

In Section 2 the state of the art is sketched. Afterwards, the experience definition for the Pellucid platform is given in Section 3. The experience manifestation, presented to the employees, called active hints, is specified too. Then, the foundations of a process of the experience adaptation to the employee's needs are presented (in Section 3) together with the roles of agents participating in it (shown in Section 4). Next, Section 5 presents a detailed description of the way the agents perform activation of the active hints. Conclusions arising from 
the application of agents to experience management are presented in Section 7 together with some insight into future work.

\section{State of the Art}

There are some projects which apply agent technology to knowledge management environments. AMKM [6] is a framework, which uses agent concepts to analyse and model organisations and as a result to provide a reusable architecture to build knowledge management systems. The AMKM framework is intended to provide a common, uniform description of knowledge items for users performing different knowledge intensive tasks. Next, DIAMS is a multi-agent system which helps users to access, collect, organise and exchange information [7. The personal agents are exploited to provide their owners with well-organised information collections, as well as friendly information management utilities. The CoMMA project 8] implements a corporate memory management framework based on agent technology, that captures, stores and disseminates knowledge to support users' work with documents. Ontologies are exploited to annotate documents in the corporate memory.

In general the scientific community tries to support employees by providing a service called Organisational Memory 910]. Such a memory is treated as the collector of all kinds of organisational knowledge and is specially designed for reuse in the future. The DECOR [1], FRODO [12, KnowMore 13] projects deal with such knowledge repositories. The heterogenous nature of knowledge resources implies the use of agents for managing the content of such a memory.

\section{Experience Definition and Representation}

It is assumed that an organisation follows a formalised and well established business administration process to reach its goals. The process could be supported by a Workflow Management System (WfMS). WfMS specifies in detail successive activities to be performed. Most of the activities are knowledge-intensive - they require knowledge of a miscellaneous nature to be performed correctly. Such activities require from the employees broad knowledge about how to proceed in given circumstances. The Pellucid working definition of experience uses such knowledge. Experience is a kind of knowledge concerning an action which has to be performed in a particular context.

It seems obvious that experience requires human intelligence in both creation and reuse. For the purposes of the experience management system an adequate representation of experience has to be found. Ontologies are the natural way to represent knowledge.

On ontology is a specification of conceptualisation, which is readable both by human and computer systems 14. The experience could be expressed with the help of ontology. In the frame of Pellucid operation the experience is represented by a set of active hints. The active hint is a representation of a piece of experience. According to the context of the employee's work selected hints 


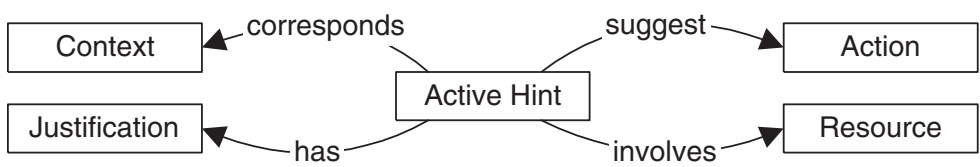

Fig. 1. Active hint definition

are presented to him spontaneously. The elements of the active hint, shown in Fig. 1 are: an action to be performed, resources involved during performing the action, a context of the employee work and justification for recommendation of the action. The justification represents possible motivation for the employee to follow the hint. During the operation the Pellucid system tracks all actions taken by employees as well as working context, and stores relevant instances of the ontologies. These instances define the employee's experience representation. Pellucid ontologies are implemented in DAML+OIL [15] and manipulated by the Java-based Jena library[16].

Profiles of Employees. Experience is a highly subjective matter in both creation and reuse. The decision whether an active hint should be shown to the employee has to take into account factors arising not only from the scope of work characteristic for a given position but also from the employee profile. The active hints which are going to be proposed to the employee have to fit the employee's needs. The expectations of the employee strongly depend on experience and skills he already possesses. According to the above criterion several types of employees are distinguished:

- Novice - a totally inexperienced employee (e.g. a recent graduate).

- New-hired or Relocated Employee - an employee who has got already some practical skills needed at the given position acquired during earlier work for another employer.

- Relocated Employee - an employee who has got already some practical skills needed at the given position acquired during earlier work in this organisation.

- Experienced Employee - an employee who has worked at the given position in the organisation for a long time (for the Pellucid system he is an experience provider).

The active hints should be adapted to the level of employee's experience - the experienced user should not be bothered with hints concerning low level skills. The adaptation of active hints also has to consider that employees' experience evolves and new skills are developed over time. Moreover, the employee's profile is defined by the employee's history of work in the organisation and with the Pellucid system.

Pellucid Formula. One of the most important issues of the Pellucid experience management system is the choice of experience which should be presented to the 
user. On the one hand there is knowledge about the role and the job the employee is assigned to. On the other hand there is experience which the employee has already acquired. The above relation could be formalised as follows:

$$
E_{G}=E_{R}-E_{A},
$$

where $E_{R}$ is experience required, $E_{A}$ is experience available due to the employee's previous activities and $E_{G}$ is the experience gap between required and available ones. The task of the Pellucid system is to present a subset of $E_{G}$ to the employee on the basis of $E_{R}$ resulting from description of his current job and role and due to $E_{A}$ derived from the employee's profile.

\section{Experience Management Agents}

Based on Eq. 1 the areas of responsibility for elements of the system can be defined. The agent technology fits the Pellucid system features well. Cooperating, intelligent, autonomous agents can be exploited to achieve the overall goals of Pellucid, i.e, reuse of experience to assist the employees.

As mentioned before, the system should find the experience gap for an employee accomplishing a task within a performed role. Therefore, two main components are introduced : Role Agent (RA) and Personal Assistant Agent (PAA). The purpose of RA is to find experience required for a particular role $\left(E_{R}\right)$. PAA is responsible for finding experience of a particular employee $\left(E_{A}\right)$. The required experience is not only related to the role of the employee but it also depends on the task the employee is performing. So, Task Agent (TA) is introduced to find out what part of experience is required for accomplishment of a particular task. PAA cooperates with RA and TA agents to learn about the experience gathered by the employee while playing a role. All these agents are able to find experience necessary for the employee.

Experience gathered by the agents is stored with the help of a special component called Organisational Memory (OM).

The nature of work in any organisation requires access to information resources, such as documents, e-mails, databases, etc. It is necessary to ensure fast and uniform access to information resources and allow extraction of the information and knowledge from them, since the experience is not only just knowledge of how to perform a required task, but also often knowledge extracted from organisational assets, i.e. documents and data. This task is performed by Information Search Agent (ISA), being responsible for accessing document repositories, other external resources and searching using full-text indexing, document similarity strategies and ontology searching.

To provide active assistance the system has to track employees' activities and the context which they are working in. Therefore, two agents, Monitoring Agent (MA) and Environment Tracking Agent (ETA) are introduced respectively.

In Fig. 2 the components involved in $E_{G}$ computation are presented. 


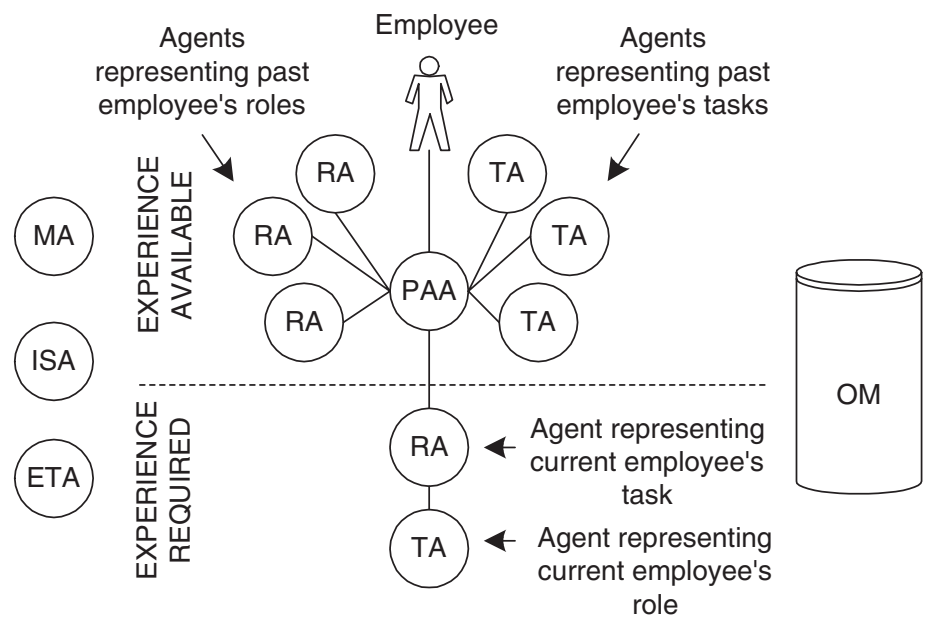

Fig. 2. Pellucid agents

\section{Activation of Active Hints}

Several methods could be invented to deal with Eq. 1. A method, which allows finding active hints to be presented to the employee, is proposed below.

The factors influencing activation and deactivation of active hints can be twofold - can derive from both the required and available experience. A set of factors that influence selection of the active hints can be defined. Beneath there are some examples of the critical factors:

- The employee has already been working on an activity with a similar context.

- Skills of the employee refer to the skills represented by the active hint.

- Employee's actions have been used to instantiate the active hint.

The approach can be formalised as follows. Thus, $E$ is a set of employees, $H$ is a set of active hints and $F$ is a set of functions for computing different factors:

$$
\begin{aligned}
& E=\left\{e_{1}, e_{2}, \ldots, e_{n}\right\}, \quad \text { where } \quad n \in \mathbf{N}, \\
& H=\left\{h_{1}, h_{2}, \ldots, h_{m}\right\}, \quad \text { where } \quad m \in \mathbf{N}, \\
& F=\left\{f_{1}, f_{2}, \ldots, f_{l}\right\}, \quad \text { where } \quad l \in \mathbf{N} \text {. }
\end{aligned}
$$

The activation function is

$$
A\left(f_{1}, f_{2}, \ldots, f_{l}\right) \in(0,1) .
$$

where $f_{i}\left(e_{j}, h_{k}\right)$, is the factor function.

The activation function takes all factor functions $f_{i}$ for a given active hint $h_{k}$ for a particular employee $e_{j}$ and returns a normalised rating value. The activation function is computed for each active hint. The active hints are rated according to the value of the activation function - the greater the value, the more relevant is the active hint for the particular situation. 
Table 1. Activation function computation for a particular employee

\begin{tabular}{|c|c|c|c|c|}
\hline$e_{j}$ & $h_{1}$ & $h_{2}$ & $\ldots$ & $h_{m}$ \\
\hline$f_{1}$ & $f_{1}\left(e_{j}, h_{1}\right)$ & $f_{1}\left(e_{j}, h_{2}\right)$ & $\ldots$ & $f_{1}\left(e_{j}, h_{m}\right)$ \\
$f_{2}$ & $f_{2}\left(e_{j}, h_{1}\right)$ & $f_{2}\left(e_{j}, h_{2}\right)$ & $\ldots$ & $f_{2}\left(e_{j}, h_{m}\right)$ \\
$\ldots$ & $\ldots$ & $\ldots$ & $\ldots$ & $\ldots$ \\
$f_{l}$ & $f_{l}\left(e_{j}, h_{1}\right)$ & $f_{l}\left(e_{j}, h_{2}\right)$ & $\ldots$ & $f_{l}\left(e_{j}, h_{m}\right)$ \\
\hline$A$ & $A\left(f_{1}, f_{2}, \ldots, f_{l}\right)$ & $A\left(f_{1}, f_{2}, \ldots, f_{l}\right)$ & $\ldots$ & $A\left(f_{1}, f_{2}, \ldots, f_{l}\right)$ \\
\hline
\end{tabular}

For each employee the following array should be computed:

The activation function exploits factor functions to determine if an active hint should be presented to the employee; for instance in the simplest case the activation function could be a sum or a weighted sum of all factors.

\section{Scenario}

The activation function is computed using software agents technology. Each agent is responsible for computing one or more factors, but to merge them all collaboration and communication between agents is necessary.

At the beginning of Pellucid's operation in the organisation, the organisational memory will be fed with the initial active hints. During regular work the system will acquire the knowledge or experience and transform it into new active hints with the help of a knowledge engineer. The graphical user interface for active hints creation is also proposed but targeted mainly to advanced users. So the system memory will grow continuously. As presented above the selection of active hints could involve many factors. We will show how subsequent factors limit the number of active hints to be shown.

We assume that two different employees are in the same working context. The system should extract only these active hints which match to the context of our two employees. By matching working context the position in the workflow tracking/management system is considered. Then the domain specific properties are regarded. They should be similar to those specified in the context of the active hint.

The user context and the problem context are as follows.

- User context in workflow system. It is a part of Working Context concerning the position of employee in business process. Active hint is candidate for activation if its context is similar to this one.

$$
\text { ProcessContext }\left(e_{j}\right) \sim \text { ProcessContext }\left(h_{k}\right)
$$

- Problem context. These are all properties describing the current problem domain. Active hint could be activated if the problem context is similar to the problem in which the active hint is valid.

$$
\text { ProblemContext }\left(e_{j}\right) \sim \text { ProblemContext }\left(h_{k}\right)
$$


Afterwards, the employee profile is taken into account. The participation in the similar tasks increases the level of expertise which in turn results in lower amount of active hints shown to the user. The active hints that recommend an action that the user is familiar with (he always performs it when dealing with such a task) are also not suggested. If dealing with a novice all active hints matching the current situation are shown. However, the skilled new hire employee also require experience assistance, but Pellucid does not contain any information about his work history. Such an employee should be classified with the level of experience and from the other side each active hint should have the type of employee it is valid for. The experience classification could be very simple (e.g. novice, basic, intermediate, advanced) or it could be a more detailed one with the description of several skills possessed by the employee. Some examples of skills are: language skills, documenting skills, cooperation skills, negotiation skills etc. Each skill might be described with the skill level: novice, basic, etc. Also any active hint could be characterised with the skills it concerned. Thus the context in workflow and the problem the user is solving determine the experience required for the current situation while the user profile represents the experience available.

\section{Conclusions}

The area of experience management systems is naturally related to agent technology. The management of experience often entails ontologies for knowledge and experience representation as well as reasoning for creation, adaptation and maintenance of the experience. The usage of agents within the Pellucid system has turned out to be profitable and effective. Reuse of experience manifested by spontaneous appearance of active hints is well suited to employees' expectations.

Acknowledgments. Thanks are due to European Commission and participants of the Pellucid project, IST-2001-34519. AGH-UST grant is also acknowledged.

\section{References}

1. Pellucid - A Platform for Organisationally Mobile Public Employees, EU IST2001-34519 Project, 2002, http://www.sadiel.es/Europa/pellucid/.

2. Słota, R., Majewska, M., Dziewierz, M., Krawczyk, K., Laclavik, M., Balogh, Z., Hluchý, L., Kitowski, J., Lambert, S., "Ontology assisted access to document repositories in public sector organizations", Proc. of 5th Int. PPAM 2003 Conf., Sept. 7-10, 2003, Częstochowa, Poland.

3. Laclavik, M., Balogh, A., Hluchý, L., Słota, R., Krawczyk, K. and Dziewierz, M., "Distributed Knowledge Management based on Software Agents and Ontology", Proc. of 5th Int. PPAM 2003 Conf., Sept. 7-10, 2003, Czȩstochowa, Poland.

4. Lambert, S., Stringa, S., Vianno, G., Kitowski, J., Słota, R., Krawczyk, K., Dziewierz, M., Delaître, S., Oroz, M.B., Gomez, A.C., Hluchý, L., Balogh, Z., Laclavik, M., Fassone, M., Contursi, V., "Knowledge management for organisationally mobile public employees", Proc. of 4th IFIP Int. Working Conf. on Knowledge 
Management in Electronic Government, KMGov 2003, Rhodes, May 26-28, 2003, Lecture Notes in Computer Science (Lecture Notes on Artificial Intelligence) no. 2645, Springer, 2003, pp. 203-212.

5. Kitowski, J., Krawczyk, K., Majewska, M., Dziewierz, M., Słota, R., Lambert, S., Alvaro, A., Miles, A., Hluchý, L., Balogh, Z., Laclavik, M., Delaître, S., Vianno, G., Stringa, S., Ferrentino, P., "Model of Experience for Public Organisations with Staff Mobility", submitted to 5th Working Conf. on Knowledge Management in Electronic Government, May 17-18, 2004, Kerms, Austria.

6. Dignum, V., "An Overview of Agents in Knowledge Management", http://www.cs.uu.nl/ virginia/amkm.pdf.

7. Chen, J.R., Wolfe, S.R., Wragg, S.D., "A Distributed Multi-Agent System for Collaborative Information Management and Sharing", Proc. of 9th ACM International Conference on Information and Knowledge Management, November 6-11, 2000, McLean, VA, USA.

8. CoMMA project, http://www.si.fr.atosorigin.com/sophia/comma/Htm/HomePage.htm.

9. Abecker, A., Bernardi, A., Hinkelmann, K., Kühn, O., Sintek, M., "Toward a technology for organizational memories", IEEE Intelligent Systems, 13(3), pp. 40-48.

10. Reimer, U., Margelisch, A., Staudt, M., 2000, "EULE: A Knowledge-Based System to Support Business Processes", Knowledge-based Systems Journal, Elsevier, Vol. 13 No. 5. pp. 261-269.

11. DECOR: Delivery of Context-Sensitive Organizational Knowledge, http://www.dfki.uni-kl.de/decor/deldec/D1-Final.pdf.

12. Abecker, A., Bernardi, A., van Elst, L., Lauer, A., Maus, H., Schwarz, S., Sintek, M., FRODO: A framework for distributed organizational memories. Milestone M1: Requirements analysis and system architecture", D-01-01, 2001, DFKI GmbH.

13. Abecker, A., Bernardi, A., Hinkelmann, K., Kühn, O., Sintek, M. "Context-aware, proactive delivery of task-specific knowledge: The KnowMore project", International Journal on Information Systems Frontiers, 2000, 2(3/4), pp. 139-162.

14. Uschold, M., and Gruninger, M., "Ontologies: Principles, Methods and Applications", Knowledge Engineering Review, 11(2), June 1996, pp. 93-137.

15. DAML - DARPA Agent Markup Language, http://www.daml.org/.

16. Jena - A Semantic Web Framework for Java, http://jena.sourceforge.net/ 